ANUARIo DE Estudios Medievales

41/2, julio-diciembre de 2011

pp. $577-591$

ISSN 0066-5061

\title{
LA TECNOLOGÍA SEDERA EN VALENCIA A LA LUZ DE UNAS ORDENANZAS INÉDITAS DEL SIGLO XV ${ }^{1}$
}

\author{
SILK-MAKING TECHNOLOGY IN VALENCIA \\ IN THE LIGHT OF SOME UNPUBLISHED ORDINANCES \\ OF THE 15th CENTURY
}

GERMÁN NAVARRO ESPINACH

Universidad de Zaragoza

Resumen: Estudio de un libro inédito de ordenanzas de los siglos XV-XVII perteneciente a los tejedores de terciopelos de seda de Valencia, conservado en The Hispanic Society of America de Nueva York. $\mathrm{Su}$ comparación con las ordenanzas valencianas de la seda conocidas hasta ahora ofrece nuevos datos sobre la tecnología textil del siglo XV.

Palabras clave: seda; terciopelo; Valencia; siglo XV; ordenanzas; tecnología textil.

\begin{abstract}
Study of an unpublished book of ordinances of the $15^{\text {th }}$ to $17^{\text {th }}$ centuries pertaining to the silk velvets weavers of Valencia, conserved in The Hispanic Society of America in New York. Its comparison with the Valencian silk ordinances that we already know provides new information on 15 th century textile technology.
\end{abstract}

Keywords: silk; velvet; Valencia; $15^{\text {th }}$ century; ordinances; textile technology.

\section{SUMARIO}

1. Un libro de ordenanzas de velluters en Nueva York.-2. Las primeras ordenanzas de 1479.-3. Las segundas ordenanzas de 1480.- 4. Terceras ordenanzas y estatutos de la cofradía de 1483.5. Las cuartas ordenanzas de 1491.-6. Conclusiones.- 7. Bibliografía citada.

\section{UN LIBRO DE ORDENANZAS DE VELLUTERS EN NUEVA YORK}

Con motivo de la exposición L'Art dels Velluters. Sederia dels segles XV$X V I$, organizada por el Consorci de Museus de la Comunitat Valenciana en el Centro del Carmen de Valencia (18 de mayo - 17 de julio de 2011), y gracias a la gentileza

${ }^{1}$ El presente estudio se integra en el programa de actividades del Grupo de Investigación de Excelencia CEMA (Centro de Estudios Medievales de Aragón) de la Universidad de Zaragoza, financiado por el Gobierno de Aragón, y en el marco del proyecto interuniversitario Elites sociales y estructuras económicas comparadas en el Mediterráneo occidental (Corona de Aragón, Francia e Italia) en la Baja Edad Media, subvencionado por el Ministerio de Ciencia e Innovación durante 2009-2011 (Ref. HAR2008-06039). 
de las comisarias de dicha muestra, María Victoria Liceras y Gertrudis Jaén, ha sido posible estudiar dos manuscritos hallados dentro de los fondos de The Hispanic Society of America de Nueva York que contenían ordenanzas antiguas del gremio de velluters de Valencia, los cuales han sido expuestos en dicha exposición junto con una colección de tejidos procedentes también de allí. Lo cierto es que ya se investigó hace años en el Archivo del Colegio del Arte Mayor de la Seda de Valencia y en otros fondos documentales de la ciudad el tema de los orígenes medievales de la sedería valenciana, y la tarea fue ardua al tener que recopilar todas las ordenanzas dispersas de los oficios implicados en este sector a falta de disponer de un compendio de las mismas en el archivo gremial ${ }^{2}$.

El más importante de esos dos manuscritos de Nueva York es el más antiguo que se titula Confraria del Gloriós Sent Ierònim. Capítols, fechado entre 1483 y 1571 con la signatura MS. HC: NS1/814 ${ }^{3}$. En sus primeros folios se especifica en castellano que se trata de un Libro de Capítulos Antiguos de Velluters. En conjunto, su extensión es de 135 folios $\left(25^{\prime} 6\right.$ x $18 \mathrm{~cm}$ ) numerados hasta el 81 en cifras romanas y desde el 82 en adelante en arábigas. No se computan en esa cuenta ni un par de folios en blanco con títulos en castellano que hay al principio del libro, ni otros tres con índices de rúbricas en valenciano que siguen a éstos y en los cuales sólo se registran los contenidos hasta el folio 43. Con todo, falta el folio 31 a tenor del salto en la numeración que se produce entre el 30 y el 32 como veremos en el último apartado del presente trabajo. Además, hasta el citado folio 81 numerado en romano el tipo de escritura es gótica libraria con letras iniciales resaltadas en cada párrafo, destacando la primera de todas ellas, miniada con la representación más antigua que se conoce de la imagen del patrón san Jerónimo. Del folio 81 en adelante la escritura es cursiva y está ejecutada por manos diversas.

Al principio de dicho manuscrito se reproducen hasta cuatro ordenanzas antiguas de velluters, las primeras de las cuales son del 16 de febrero de 1479, aprobadas por las autoridades municipales. Debe matizarse, sin embargo, que una versión inicial de esas primeras ordenanzas municipales fue redactada más de un año antes y publicada ante notario por los propios maestros fundadores de la cofradía del oficio. Concretamente, el 18 de octubre de 1477 cincuenta y seis maestros, reunidos en la casa del genovés Lazzaro Negro, sita en la calle de las Barcas de Valencia, firmaron ante el notario Bernat Sant Feliu el acta de fundación de la Lloable Confraria o Almoina de l'Ofici de Velluters bajo la advocación de san Jerónimo. Entre ellos había como mínimo otra docena de genoveses. El documento se localiza en las actas de ese notario depositadas en el Archivo de Protocolos del Colegio del Patriarca de Valencia con la signatura 1.020 .

Al comparar el acta notarial de 1477, que cuenta con 22 capítulos, con el texto definitivo de las ordenanzas municipales de 1479 , que tiene 26 , se observan algunas modificaciones de interés. Para empezar, el motivo por el que se fundaba la cofradía era la gran multitud de personas que cada día aumentaba en ese oficio y los abusos que ya se estaban cometiendo entonces. Entre esos abusos se apuntaba que algunos maestros enriquecidos tenían muchos telares en su casa y estaban acaparando el negocio entre ellos poniendo en peligro a los demás. Por ese motivo se estableció

\footnotetext{
${ }^{2}$ G. Navarro, El despegue de la industria; idem, El Col-legi de l'Art Major; idem, Los orígenes de la sederia.

${ }^{3}$ El segundo manuscrito recibe el título de Valencia. Cofradía. Capítols de Colegi y tiene la signatura HC: 387/2989. Se compone de 38 folios (29'1 x 20 cm) y reproduce el privilegio del rey Carlos II de 1686 por el que se concede el grado de Colegio y Arte Mayor al oficio de velluters y está escrito en latín y castellano con letra humanística cursiva.
} 
la norma de que no pudieran tener más de cuatro telares en propiedad (cap. 13), aunque en las ordenanzas municipales de 1479 se aumentó a cinco telares el límite. Por otra parte, en 1479 no están los capítulos 8 y 10 de los estatutos de 1477 en que se establecían los diferentes lucros o beneficios en sueldos y dineros valencianos que se pagarían a los obreros contratados por cada vara de tejido confeccionada, ni tampoco las tasas establecidas para cada tipo de urdimbre. De igual manera, en 1477 no figura la solicitud que aparece en 1479 para que los velluters sean considerados arte y no oficio. En suma, la iniciativa privada de ese medio centenar de maestros fundadores fue aprobada con enmiendas y novedades importantes tiempo después, sin olvidar que con fecha 13 de octubre de 1479 el rey Fernando II de Aragón confirmaría con un privilegio real esas primeras ordenanzas municipales concediendo el título de arte solicitado.

\section{LAS PRIMERAS ORDENANZAS DE 1479}

Estos primeros estatutos tienen pues tres versiones sucesivas que pueden conocerse ahora a través de otras copias gracias al manuscrito de Nueva York. Como ya ha quedado claro con anterioridad, la versión más antigua de esas primeras ordenanzas es el acta del notario Bernat Sant Feliu del año 1477 con 22 capítulos. Este texto con las enmiendas y novedades comentadas se aprobó por parte de las autoridades municipales el 16 de febrero de 1479. Su comparación fue posible al poder consultar también la segunda versión de dichas ordenanzas registrada en los libros de Manuals de Consells del Archivo Municipal de Valencia, signatura A-41, folios 198v-204r. No se procedió a su transcripción y publicación porque el contenido, salvo el preámbulo y el colofón, era idéntico a la tercera versión sucesiva de las mismas, es decir, al privilegio de confirmación del rey Fernando el Católico, que sí se transcribió y editó porque es sin lugar a dudas el documento más trascendente de los tres.

Lo que hace el manuscrito de Nueva York es copiar tanto el texto de las ordenanzas municipales como el preámbulo y el colofón del privilegio real. Las ordenanzas municipales ocupan los folios 1-10r y al final de las mismas se anota en párrafo aparte con letra cursiva que dicha copia es traslado fiel de annalibus et libris conciliorum et stabilimentorum civitatis Valencie, efectuado por el notario Jaume Eximeno, escribano real y notario de los jurados de Valencia, sin especificar fecha pero poniendo el signo notarial correspondiente. Se entiende que es el traslado que se entregó el mismo día de su aprobación para el archivo del oficio de velluters, inaugurando de esa manera los primeros folios de este libro de ordenanzas. En consecuencia, la cronología con que aparece catalogado dicho manuscrito en los fondos de The Hispanic Society of America es incorrecta, puesto que su punto de partida debe ser 1479 en vez de 1483 .

Pero el oficio de velluters, como se ha dicho, no se conformó con la aprobación municipal de sus ordenanzas y solicitó al rey Fernando el Católico la ratificación de las mismas con especial énfasis en la concesión del privilegio de denominarse arte y no oficio. El 13 de octubre de 1479 el monarca emitió el documento en cuestión. La única copia que logré del mismo la encontré en el Archivo del Colegio del Arte Mayor de la Seda de Valencia. Era el pergamino número 8 de la Sección 1 de los fondos $(580 \times 616 \mathrm{~mm}$.). Pero es un traslado bastante posterior del notario valenciano Jaume Pellicer para el archivo del gremio, fechado el 25 de octubre de $1514^{4}$. En ese sentido,

\footnotetext{
${ }^{4}$ Transcrito íntegro en la memoria de licenciatura de G. Navarro, El despegue medieval, doc. 5 , pp. 466-479. Publicado posteriormente en el estudio del mismo autor titulado Los privilegios reales, pp. 197-231, en concreto doc. 3, pp. 226-231.
} 
una de las aportaciones más interesantes que nos ofrece el manuscrito de Nueva York es que reproduce parcialmente dicho privilegio en sus folios $20 \mathrm{r}-21 \mathrm{v}$, es decir, evita repetir las primeras ordenanzas municipales que confirma y que ya las había copiado antes, y se limita a copiar el preámbulo y el colofón del privilegio.

A renglón seguido, la traducción al español actual del índice de rúbricas en catalán medieval correspondiente a estas ordenanzas sintetiza bien los contenidos generales de las mismas. Se trata de un total de 26 capítulos que aluden a la institución de la fiesta patronal, la manera de elegir al clavario y a los mayorales y veedores de la junta rectora, las cuotas que deben pagar los maestros por estar inscritos o, de manera especial, la tipología de tejidos, la prueba de examen, etc. Aspectos todos ellos relacionados con la estructura administrativa de la entidad y con el afán de monopolio de la mano de obra y del mercado locales. Las rúbricas del manuscrito de Nueva York lo organizan así:

[1] De la fiesta que debe ser hecha el día de san Jerónimo.

[2] Que los maestros sean convocados la víspera de san Jerónimo.

[3] La manera de la elección de mayorales, examinadores y veedores.

[4] La manera de la elección del clavario y del cargo de aquél.

[5] De lo que debe pagar cada maestro y obrero.

[6] La forma cómo se deben pagar los tres sueldos y cuatro dineros.

[7] Del cargo que tiene el clavario.

[8] El clavario no pueda por si hacer ningún gasto.

[9] De la cuenta que tiene que dar el clavario.

[10] Que el clavario deba tener inscritos todos los maestros.

[11] Las tramas que son prohibidas.

[12] Los pintes cuántas ligaduras deben tener.

[13] Ninguno pueda tener más de cinco telares.

[14] Ninguno pueda tener telares si no es maestro examinado.

[15] Ninguno pueda ser examinado si no ha estado cinco años con maestro.

[16] Del examen y de la manera de la paga.

[17] Ningún maestro pueda coger aprendiz sino es para tiempo de cinco años.

[18] Ningún maestro pueda coger mozo ni obrero de otro maestro.

[19] Ninguno goce tener telar si no es maestro o bajo maestro examinado.

[20] De los que estaban en el oficio antes de la realización de los capítulos.

[21] Quien comienza tela sea obligado a acabar aquélla.

[22] Que ningún obrero pueda partir del maestro sino en cierta manera.

[23] Que ninguno pueda tener telar hasta que será examinado.

[24] De los extranjeros que quieren ser examinados.

[25] De los trabajadores que romperán cualquier herramienta que paguen.

[26] Que las penas sean ejecutadas por el oficio o por quien el oficio elegirá.

Los capítulos más destacados para la historia de la tecnología sedera del siglo XV son seis, a saber, los números 10,11, 12, 13, 23 y 25. El número 10 plantea la obligación para el clavario de registrar en un libro la cifra de telares que poseía cada maestro. La puesta en práctica de dicho estatuto sólo consta que se produjera en el primer libro de cuentas del oficio que se conoce correspondiente a 1479-1480: 1 maestro con 5 telares, 6 con 4, 15 con 3, 24 con 2 y 50 con 1, es decir, un total de 96 maestros que sumaban juntos 172 telares. Si el clavario rehusaba hacerlo o dilatava el recuento podía ser encarcelado a petición de los mayorales hasta que con- 
cluyera esa tarea. Sin embargo no consta que algo así sucediera nunca, a pesar de no haberse conservado más recuento que ese primero citado. Por añadidura, el capítulo 13 completa al anterior al establecer un límite máximo de 4 o 5 telares por maestro, algo que siete artesanos alcanzaron en el recuento de 1479 como se ha podido ver, es decir, uno de ellos con cinco telares y los otros seis con cuatro. Por debajo de ellos había un colectivo de quince artesanos más con tres telares cada uno. Sin duda, a esos 22 maestros en total que poseían entre 3 y 5 telares iba dirigida la advertencia del capítulo 13 de que si superaban el límite de telares por cabeza los perderían y pagarían una multa de 20 florines por cada uno de más que tuvieran de los permitidos. La justificación de tal medida era que había algunos maestros que como tenían gran negocio podían acabar teniendo muchos telares y causarían la ruina de todos los otros maestros del oficio.

La pieza clave de la tecnología de los tejedores de seda era evidentemente el telar, aunque el estatuto número 25 detalla un poco más las herramientas comunes que se consideraban fundamentales para el ejercicio de la profesión, sancionando a los obreros que las rompieran, gastaran o perdiesen: pintes, hierros, lanzaderas y tijeras o cualquier otra artillería de sus maestros. El capítulo 11 es mucho más interesante, si cabe, por cuanto cita los primeros tipos de tejidos y tramas que se consideraron competencia exclusiva del oficio en el momento de su fundación: terciopelos, satenes y damascos de seda pura. Quedaban prohibidas las denominadas tramas falsas con mezclas de hilo de algodón o con fibras séricas defectuosas como el cadarzo o el filadiz. Por cada vez que se encontrase una seda falsa, es decir, con mezclas de seda y otra fibras se pagarían 50 florines de oro de castigo y la pieza sería quemada.

En el siguiente estatuto, el número 12, se concretan todavía más las características de los pintes con los que se debían de confeccionar dichos tejidos. El vellut senar o terciopelo único tendría como máximo 22 ligaduras, el terciopelo común 21 y el terciopelo doble, llamado así por ser velludo por ambos lados, hasta 20. Los tejidos de setí o satén podrían alcanzar también las 20 ligaduras, y el domàs o damasco las 24. Si se incumplían estos límites las telas serían quemadas y la multa a pagar por cada una de ellas que incumpliera la ordenanza sería de 20 florines de oro.

Por último, el capítulo 23 subraya además la obligación de cumplir una estricta correspondencia entre los tipos de telares que posean los maestros y las pruebas concretas de examen que hayan superado. Es decir, sólo se podía tener telares con pintes específicos de los tejidos en los que se tuviera reconocida competencia técnica. Si únicamente se había superado la prueba de magisterio en tejer damasco sólo se podía tener en casa telares con pintes preparados para tejer damasco y así con el resto. En ese sentido, gracias a los primeros exámenes registrados en los libros gremiales se tiene constancia de que la gran mayoría de los telares que hubo en el momento de la fundación del oficio era de terciopelo y satén y en menor medida de damasco. Quien contradijese esta ordenanza pagaría una multa de 100 sueldos.

\section{LAS SEGUNDAS ORDENANZAS DE 1480}

Las segundas ordenanzas, tal y como aparecen denominadas en el manuscrito, fueron aprobadas por las autoridades municipales el 9 de septiembre de 1480 . Una versión original de las mismas ya fue localizada en su día tras una revisión exhaustiva de los libros de actas de la serie de Manuals de Consell del Archivo Munici- 
pal de Valencia, signatura A-42, folios $32 \mathrm{v}-37^{5}$. A través de los folios $11 \mathrm{r}-18 \mathrm{v}$ del libro de ordenanzas del gremio que acabó en Nueva York se conoce el traslado coetáneo que efectuó Jaume Eximeno, notario de los jurados valencianos. La traducción de sus rúbricas sintetizan a continuación los contenidos de los 28 capítulos de esta segunda normativa:

[1] Corrigiendo al tercer capítulo de la primera ordenanza que contiene la manera en que se debe hacer la elección de los mayorales.

[2] Corrigiendo y mejorando al quinto capítulo de la primera ordenanza que contiene cómo se deben pagar los 4 sueldos y 4 dineros.

[3] Mejorando el noveno capítulo de la primera ordenanza que contiene la manera de la cuenta que ha de dar el clavario.

[4] Adición al vigésimo cuarto capítulo de la primera ordenanza que contiene que los obreros deben ser manifestados y lo que tienen que pagar.

[5] Que los mayorales viejos sean consejeros.

[6] Que los mayorales se puedan reunir.

[7] Que los oficiales no puedan entrar en el oficio del que saldrán hasta cierto tiempo.

[8] La manera en que son convocados a capítulos.

[9] Ninguno que sea entrante en el oficio pueda entrar en elección.

[10] La pena de quien hablará en capítulo antes de que le venga el voto.

[11] Cómo los maestros deben oir misa antes de entrar en capítulo.

[12] Los cirios que se deben hacer en el oficio.

[13] De dónde debe hacerse el examen.

[14] Que los mayorales sean francos de los capítulos.

[15] El honor que debe ser hecho a los que mueren en el oficio.

[16] Que la viuda no pueda tener los telares sino sólo el año de la viudedad si no tiene hijos o en cierta manera.

[17] Adición al décimo primer capítulo de la primera ordenanzas que contiene de las tramas.

[18] Aumentando el décimo segundo capítulo de la primera ordenanza que contiene en qué cuenta debe ser tejido el camelote.

[19] De los paños falsos.

[20] De los veedores y del poder de aquéllos.

[21] De las penas y de la partición de aquéllas.

[22] Que los paños hechos fuera de la ciudad deben ser marcados.

[23] De jurisdicción de seda no recibidora.

[24] Cómo los mayorales pueden poner pena a los desobedientes.

[25] Ninguno goce mostrar el oficio sino a su mozo y afirmado, y ningún maestro pueda hacer daño a su mozo.

[26] Que el clavario pueda hacer jurar a los maestros sobre el afirmamiento de los aprendices.

[27] Adición al cuarto capítulo de la primera ordenanza que contiene de quien quiere ir como obrero y a qué es obligado.

[28] Corrigiendo el tercer capítulo de la primera ordenanza que contiene cómo se debe hacer la elección de los veedores.

En algunos casos se trata de reformas, adiciones o correcciones a las primeras ordenanzas. Por ejemplo, se elimina la tasa anual de 4 sueldos y 4 dineros que debían pagar los maestros por cada telar que tuviesen en propiedad (cap. 2) y se insiste en vigilar el uso de fibras impuras para la confección de los tejidos (caps. 19-20). Otros temas importantes que subyacen son las sanciones por inobediencia y fraudes

${ }^{5}$ G. Navarro, El despegue medieval, doc. 6, pp. 480-492. 
en la producción o en la contratación de mano de obra. Por su valor especial para el estudio de la tecnología sedera merecen comentarse los capítulos 17, 18, 19, 20, 22 y 23. En ese sentido, en el número 17 se detallan más los tipos de fibras consideradas impuras o falsas y, por tanto, prohibidas para la confección de los tejidos del oficio: hilo filadiz, algodón, cadarzo, aldúcar, primichol o escumara. Al margen del algodón mezclado con seda se trata de hilos derivados de capullos rotos o residuales de su cocción, o bien defectuosos por una mala manipulación durante la fase de extracción e hilado.

En el capítulo 23 se regulan también los conflictos derivados de la compraventa de madejas de seda de color verde o amarillo, que tienen esos colores en función de la especie de gusano o de la alimentación que se les da, sin que por ello se prohiba una u otra variedad, pero ante cualquier denuncia las autoridades municipales arbitrarán las medidas oportunas con el asesoramiento de los veedores del art de velluters. La obsesión por perseguir el fraude contra las tramas de seda fina o pura llevó a los maestros a proponer sanciones contra cualquier fibra procedente incluso de fuera del reino que se descubriese en la ciudad y su término tal y como se recoge en el capítulo número 19. En él se detalla hasta una multa de 60 sueldos y la pérdida de las telas contra quienes incumplan esta normativa. Se contempló incluso en el capítulo 20 la posibilidad de que los veedores del oficio vigilasen una o más veces por semana los tejidos existentes en las casas de los artesanos y mercaderes de la ciudad para luchar contra el fraude. El objetivo perseguido era ni más ni menos que la creación de una marca o denominación de origen que certificase la calidad y la pureza de los tejidos de seda valencianos. Sin embargo, que se sepa no se conserva ningún tejido de seda del siglo XV en el que pueda verse la señal de la ciudad de Valencia ni la de cualquier otra población. De hecho, la exposición de tejidos procedentes de la colección textil de The Hispanic Society of America que se ha celebrado en Valencia no recoge ningún ejemplo. Es sin duda el sueño de los conservadores de museos y de los especialistas en este tema para poder catalogar la procedencia de un tejido antiguo, pero la repetición de patrones y modelos por todo el Mediterráneo de aquella época dificultan su identificación y, menos aún, saber en el taller de qué maestro concreto se efectuó. Por último, cabe destacar el capítulo 18 de estas segundas ordenanzas de 1480 porque añade a la oferta oficial de tejidos de la corporación de velluters uno más que es el chamellot o camelote (pelo de camello) de seda con un máximo de 17 ligaduras.

\section{TERCERAS ORDENANZAS Y ESTATUTOS DE LA COFRADÍA DE 1483}

Con el texto de las terceras ordenanzas de velluters, aprobadas por las autoridades municipales el 18 de febrero de 1483, sucede lo mismo que con las anteriores, es decir, su contenido ya se conocía a través de los libros de actas de la serie de $\mathrm{Ma}$ nuals de Consell del Archivo Municipal de Valencia, signatura A-43, folios 92-94r ${ }^{6}$. Por su parte, el traslado que recoge el manuscrito de Nueva York a lo largo de sus folios 22r-25v es una copia efectuada por el notario de los jurados para el archivo del gremio. A diferencia de la veintena larga de capítulos de las dos primeras ordenanzas, estas terceras son breves tal y como refleja la traducción de las rúbricas del manuscrito de The Hispanic Society of America:

\footnotetext{
${ }^{6}$ G. Navarro, El despegue medieval, doc. 7, pp. 493-498.
} 
[1] Que sean conservados de hoy en adelante los capítulos de las tramas prohibidas.

[2] Los paños de seda que serán traidos a la presente ciudad de Valencia sean manifestados en el plazo de tres días al magnífico almotacén.

[3] Corrigiendo y mejorando el $27^{\circ}$ capítulo de la segunda ordenanza que contiene que los obreros deban estar cinco años antes de que vayan como obreros según es ordenando en lo que aprenden en Valencia.

[4] Corrigiendo el $19^{\circ}$ capítulo de la primera ordenanza que contiene que ningún obrero ni aprendiz pueda tejer tela alguna por sí.

[5] El poder que tienen los jurados de decretar sin consejo los capítulos que hará el arte.

La lectura de estas terceras ordenanzas pone de manifiesto cómo la principal preocupación de los mayorales del arte en esos momentos era la injerencia de los comerciantes en la industria local, y más en concreto los paños de seda falsos que vendían los mercaderes genoveses (cap. 1). De hecho, dichos mercaderes utilizaban tramas falsas con mezcla de fibras de diferentes calidades para abaratar los costes de producción, contratando artesanos asalariados que trabajaban a destajo en sus domicilios, incumpliendo pues las normas corporativas del arte en materia de mano de obra y mercado. De forma paralela, se observa también el uso que hacían los mayorales del privilegio real de arte para comenzar a reunirse libremente sin la vigilancia del municipio (cap. 5). En suma, los dos primeros capítulos reflejan muy bien el esfuerzo de monopolio desplegado por los terciopeleros de seda para frenar la injerencia del capital comercial extranjero en la esfera de la producción local.

Al margen de esas terceras ordenanzas, gracias al manuscrito de Nueva York pueden conocerse ahora unos estatutos inéditos del 20 de agosto de 1483 que regularon internamente la cofradía del gremio de velluters bajo la advocación de san Jerónimo. Aparecen registrados en los folios 33r-40v del citado manuscrito y son una de las grandes novedades que aporta respecto a lo que se sabía hasta ahora. Como mucho se pudo localizar un inventario de los bienes de la cofradía del año 1496 en uno de los libros de cuentas. Se ubicaba en la casa primitiva del actual Colegio del Arte Mayor de la Seda, cuya escritura de venta del año 1494 también se localizó a la par que los gastos de la obra de la escalera de caracol gótica de los años 1506-1507 que aún se conserva ${ }^{7}$. Aunque no contiene informaciones sobre la tecnología sedera del siglo XV, es interesante reproducir a continuación la traducción de las rúbricas de estos 29 capítulos inéditos de la cofradía fechados en el año 1483 que reproduce el manuscrito de Nueva York en sus folios 33r-40v:

[1] El poder de tener cofradía y todas las cosas para el servir de aquélla.

[2] La cofradía pueda tener andadores y mozos.

[3] La cofradía pueda tener y portar cirios y bancos.

[4] De los que está obligada a enterrar la cofradía.

[5] Los cofrades están obligados a honrar las bodas y esponsalicios de los cofrades.

[6] Cómo los cofrades y cofradesas són obligados a ir a las sepulturas.

[7] Si muere el cofrade y tiene mujer, que permanezca cofradesa si querrá.

[8] Si estará alguno enfermo puedan elegir el clavario y los mayorales.

[9] La manera cómo se deben recibir los cofrades.

[10] El poder que tiene la cofradía para ofrecer y celebrar misas y aniversarios.

${ }^{7}$ G. Navarro, El despegue medieval, pp. 146-148; idem, El Col-legi de l'Art Major, pp. 101-106. 
[11] El poder que tiene la cofradía de comprar casa y casas.

[12] El poder que tiene la cofradía de hacer joyas.

[13] La pena que hay para los desobedientes.

[14] Los cuerpos de los cofrades por quiénes deben ser llevados a enterrar.

[15] Que el clavario y los mayorales se puedan reunir.

[16] Que todos los maestros sean cofrades.

[17] Lo que paga quien quiere salir de la cofradía.

[18] Que el clavario y los mayorales puedan empeñar.

[19] Que ninguno entre con armas en el capítulo.

[20] Que si entre algunos cofrades hay discusión que el clavario y los mayorales puedan forzar a aquellos a hacer la paz.

[21] Que la cofradía pueda hacer una tasa por maestro.

[22] La manera cómo deben ser recibidos los cofrades y cofradesas.

[23] Que las mujeres de los maestros y cofrades no paguen nada de entrada si quieren ser cofradesas.

[24] Que el clavario sea obligado a poner en la caja los dineros que recibirá de cada capítulo.

[25] Los salarios que deben tener los andadores y mozos.

[26] A los que la cofradía es obligada a enterrar.

[27] Qué deben pagar los cofrades y cofradesas cuando mueren.

[28] La pena que debe tener quien jura en capítulo.

[29] Los cofrades y cofradesas estén obligados a tener la fiesta de san Jerónimo.

\section{LAS CUARTAS ORDENANZAS DE 1491}

A partir de 1483, la autonomía de los velluters para dictar sus propias ordenanzas sin vigilancia municipal, gracias al privilegio del rey Fernando el Católico, desvirtuó la estrategia de investigación consistente en rastrear si se conservaban textos de ordenanzas posteriores a esa fecha en la serie de Manuals de Consell del Archivo Municipal de Valencia o en la documentación del Archivo del Colegio del Arte Mayor de la Seda. Entre las noticias sueltas que se encontraron en las actas municipales estaba la solicitud del oficial Pere Adrover para que se le reconociera como maestro acusando a los examinadores de perjudicarle (1486); el juicio de diferentes velluters sobre una pieza falsa (1487); la confiscación del dinero de la caja gremial a los mayorales por parte de las autoridades municipales obligándoles a realizar una procesión (1493); la reducción a la mitad de la tasa de examen por decreto municipal con la protesta inmediata de los mayorales que derivó en el reconocimiento como maestros a favor de dos genoveses (1495); la reforma de un capítulo de las ordenanzas sobre la confección de damascos (1501); o la intervención municipal en un pleito contra los tintoreros de seda $(1510)^{8}$. Como puede observarse, frente al autogobierno de L'Art de Velluters, el municipio valenciano servía de instancia de apelación contra los supuestos abusos cometidos por los mayorales, lo cual le permitía intervenir en sus decisiones todo lo que podía.

Que los mayorales seguían ejerciendo su autonomía política frente al municipio lo certifican las cuartas ordenanzas del 23 de noviembre de 1491 que reproduce el manuscrito de Nueva York en sus folios 25v-32v. No aparecieron en las actas municipales tal vez porque más allá de someterse a la simple aprobación de los jurados obtuvieron el visto bueno del gobernador del reino, y los jurados no debieron conside-

\footnotetext{
${ }^{8}$ G. Navarro, El Col-legi de l'Art Major, pp. 42-43.
} 
rar necesaria su plasmación en los libros de actas de la institución. Al margen de ello, debe hacerse constar que falta parte del colofón de las mismas porque no está el folio 31 del manuscrito como se dijo al principio de este artículo, con lo que tal vez haya algún capítulo más de los quince cuyas rúbricas inéditas traducidas se reproducen a renglón seguido:

[1] De tramas prohibidas.

[2] Sólo maestro examinado pueda tener mozo o aprendiz.

[3] Que todo extranjero queriéndose examinar en dicha arte se deba hacer vecino de la dicha ciudad.

[4] Que el maestro examinado no pueda dar sino calzar y vestir a los aprendices y que deban hacer faena en su casa propia.

[5] De los mozos de la dicha arte.

[6] Que sólo maestro examinado goce tener telar o telares.

[7] Que el vendedor de ropa de satén sea obligado a manifestar al comprador de cuántos lizos es satén.

[8] De los que se querrán examinar en dicha arte.

[9] Que ni a esclavo ni a persona puesta en cautividad sea mostrada dicha arte.

[10] Que a infiel no sea mostrada dicha arte.

[11] Que maestro examinado no pueda tener sino dos aprendices.

[12] Que todo extranjero sea obligado a mostrar testimonial del dicho oficio antes de que como obrero use de aquél.

[13] Los que están obligados a pagar el timbre a la caja.

[14] Que aprendiz de algún maestro en casa de otro maestro no pueda hacer faena.

[15] Que hijo de maestro examinado queriéndose examinar en dicha arte no sea obligado a pagar nada por el examen.

Para el tema de la tecnología sedera vale la pena reseñar los capítulos 1 , $3,7,9,10,11$ y 12 . De hecho, el primer capítulo confirma en 1491 la oferta oficial de tejidos originada en 1479 con una salvedad, el denominado vellutat o terciopelo aterciopelado, del que más que un tipo de paño distinto parece tratarse de una forma de acabado especial presente en cualquier terciopelo y que lo singulariza con ese nombre. Se reproduce a continuación la transcripción inédita de este primer capítulo:

[1] E primerament per provehir als fraus e decepcions que de cada dia se fan en lo obrar e lavorar dels dits draps de vellut, vellutat, domasos, cetins e chamellots, e que los qui aquells compren no sien decebuts e enguanats, e axí per utilitat e bé de la cosa pública de la present ciutat e reputació e stima de aquella en la qual los dits draps de seda per los de la di/f. 27r/ -ta art se lavoren, e s'obren e fan, millorant, corregint e aiustant als capítols atorguats a la ditta art e, o, de nou ordenen e statuexen que nengú no puxa tramar negun drap de seda, ço és, vellut, vellutat, domàs, cetí ne chamellot ab trama de seda que sia crua en cars que la seda fos fina, per ço com tal draps axí tramats e lavorats serien e són falsos e furtament fets, per quant la seda crua e la trama crua talla la seda cuyta e los qui compren los dits draps no poren tenir conexença de les dittes trames. E axí pensen-se comprar bona roba e compren la falsa. E qualsevol persona que $a b$ trama de seda crua los texirà $o$ farà texir $o$ tendrà en son poder tals draps axí texits, ara aquells sien stats obrats o texits en la present ciutat e regne o fora de aquell, puix sien trobats en la present ciutat e regne, aquells tals draps com ha falsos sien executats e la persona e persones qu.els hauran texit e lavorat o en poder de qui tals draps ésser executats en pena de dos-cents sous, dels quals dits draps e pena de dos-cents sous 
sien fetes tres parts, la una aplicadora als còfrens del senyor rey e l'altra a la ciutat, e l'altra als vehedors de la dita art, e si y havia accusador la part dels vehedors sia partida per terç ab lo accusador.

El tercer capítulo por su parte refleja la alta movilidad laboral que se está viviendo en este sector industrial de la ciudad de Valencia. La presencia habitual de extranjeros e inmigrantes que acceden al examen de magisterio obliga a establecer un requisito previo que garantice el asentamiento estable en la urbe y evite su emigración a otros lugares una vez obtenida la cualificación técnica necesaria. De ahí que se exija el avecindamiento de quienes deseen acceder al examen con la necesidad implícita de habitar en una casa de la ciudad como hace cualquier vecino de pleno derecho:

[3] Ítem més, ordenen e statuexen que qualsevol stranger de la present ciutat o regne que viu a la present ciutat e iuxta forma de les ordenacions e capitols de la dita art e offici en ell se volrà examinar en aquella dita art per poder usar de la dita art, ans que al dit examen sia admès haia a mostrar ésser-se desaveynat de la pròpia terra e pàtria de aquell e que sia fet vehí de la present ciutat en la qual tingua sa casa e habitació com ha vehí de aquella, e en altra manera no puirà ésser admès al dit examen ni examinar-se en la dita art ni puirà usar de aquella, e si en aquella art admetre se volrà encorregua en pena de doents sous e perdre los telers e altres coses que tindrà per a la dita art, partidores les penes, teles e telers en la forma que /f. 28r/ en lo present capítol és dispost e ordenat.

De la misma manera, el capítulo 12 exige a los extranjeros una carta testimonial que confirme su formación como aprendices en sus ciudades de origen y en casa de maestros examinados por las corporaciones allí existentes:

[12] Ítem, per quant sovint se sdevé que los strangers del present regne venen a la present ciutat e regne per voler usar de la dita art e offici de velluters e no hauran stat ab mestre examinat, e axí obren axí velluts, vellutats, com cetins, domasos e chamellots que no són obrats segons art de velluters, ordenen e statuexen que ans que lo tal stranger volrà usar com ha obrer de la dita art mostre e sia tengut mostrar ab carta testimonial lo temps que haurà stat $\mathrm{ab}$ mestre examinat en la dita art. E si ab carta testimonial no u mostrarà no puixa usar de la dita art com ha obrer e menys mestre examinat no el puixa pendre ni donar-li fahena com ha obrer, ans haia de star ab mestre examinat com haprenediç. E si lo contrari era fet axí lo dit jove qui volrà usar de la dita art com lo mestre examinat qui com ha jove lo tendrà encorregua cascú de aquells en pena de dos-cents sous partidors per terç en la manera en los prop precedents capítols contenguda, no obstant qualsevol capítol en contrari fins ha huy fos stat ordenat per la dita art a aquells atorguat e auctoritzat.

El capítulo séptimo plantea las dificultades que manifestaban los propios compradores de tejidos de seda en el mercado para saber cuántos lizos o ligaduras tenían los satenes que adquirían, puesto que en ciertas ocasiones los vendedores les engañaban. Entra aquí en juego la aspiración del arte por controlar el comercio local y garantizar la honestidad de la oferta procedente de su ámbito técnico, a la vez que se evidencia la complejidad técnica de sus productos y las dificultades de identificación de los mismos para la clientela común de la ciudad:

[7] Ítem, perquè los compradors dels cetins no sien decebuts e enguanats ordenen e statuexen que qualsevol persona qui vendrà o farà venda de 
cetí o cetins en gros o en menut sia tengut e haia a manifestar e dir al comprador 0 compradors de quants liços és lo cetí o cetins que vendrà $o$ farà venda en manera que lo comprador sàpia quina roba compra e no sia decebut ni enganat. E si lo contrari era per lo dit venedor fet lo tal cetí o cetins sien perduts e ultra la pena de perdre lo cetí o cetins encorregua dit venedor en pena de dos-cents sous partidors, axí los dits cetins com la dita pena peccuniària axí com en los prop e precedents capítols és ordenat.

Uno de los estatutos más interesantes de estas ordenanzas de 1491 para la historia de la tecnología sedera es el noveno, en el cual se prohibe que el oficio sea desempeñado por personas en cautividad, excepto cuando se les utiliza para mover los tornos de seda o para anudar y tirar los lazos en los telares de damascos, por cuanto ambas faenas son las más trabajosas. Lo que quiere decir que en el taller de un velluter no sólo se confeccionaban tejidos sino también se torcía el hilo de seda en tornos, labor propia de los torcedores de seda. En realidad, a pesar de existir oficios independientes especializados en cada una de dichas fases, fue la corporación más potente, L'Art de Velluters, la que acaparó en Valencia para sí competencia sobre todas ellas, incluidas las labores de tinte de los paños, con los consiguientes pleitos con el resto de los oficios sobre todo en el primer cuarto del siglo XVI.

[9] Ítem, per quant la dita art de velluters és molt honorosa e delicada e tal que deu ésser exercida per persones líberes e franques e fora de tot captiveri e servitut de captivitat, statuexen e ordenen que mestre o obrer o aprenediz o qualsevol persona per privilegiada que sia no puxa mostrar la dita art e offici de velluters ha sclau algú ni a persona que sia posada en captivitat, exceptat emperò lo menar del torn de la seda e nuar aquell e tirar los laços al teler del domàs, per quant són coses treballoses e tals que no és cosa impertinent per los catius se puxa fer, car fent-se lo contrari se /f. 30r/ se porien seguir inconvenients e scàndels de la dita art e offici, e si lo contrari per algú era fet lo contrafahent encorregua en pena de trescents sous e perdre lo catiu, la qual pena sia partida e lo preu del catiu en tres parts, segons en los props precedents capítols de partició de draps perduts e pena peccuniària és ordenat.

El capítulo 10 extiende la prohibición de ejercicio de la profesión a los llamados infieles, es decir, moros y judíos, sin establecer excepción como en el caso de los cautivos aceptados para las faenas más pesadas de los tornos o de los telares de damascos:

[10] Ítem, per ésser la dita art tant notable e de tanta valor e stima e és cosa decent que a negun infel no sia mostrada sinó que per cristians aquella haia ésser exercida, statuexen e ordenen que mestre o obrer o aprenediç de la dita art o altra qualsevol persona palesament ni amaguada no puxen mostrar la dita art e offici de velluters a moro ni ha juheu, e si lo contrari era fet, axí la persona qui lo $\cdot y$ mostrarà com encara lo moro $\mathrm{o}$ juheu a qui ho mostrarà encorregua en pena de tres-cents sous, partidora la dita pena per terços en la manera en los prop precedents capítols contenguda.

La peculiaridad de los telares de damasco reconocida por estas ordenanzas se corrobora con el capítulo 11 en el que se establece un máximo de dos aprendices al servicio de cada maestro, salvo en el caso de los maestros tejedores de damascos que podrán tener hasta tres aprendices cada uno. Recuerdo que el damasco alcanzaba el 
máximo número de ligaduras entre todos los tejidos que producía este oficio, hasta 24 según las ordenanzas. Además, eran paños con trama de tafetán y urdimbre de raso, los más complicados de elaborar de toda la tipología ofertada por el arte:

[11] Ítem, perquè la dita art sia millor exercida e no se segueixquen los abusos, fraus, scàndels e decepcions que entre los mestres e aprenediços de la dita art de velluters se acustumen fer e seguir de cada dia, ordenen e statuexen que negun mestre examinat en la dita art no puxa tenir sinó tant solament dos moços aprenediços e no més per axercici de la dita art e offici de velluters, e si més de dos moços aprenediços tendrà encorregua en pena de tre-cents sous partidors per terç en la manera en los /f. $30 \mathrm{v} /$ prop precedents capítols contenguda, exceptat los mestres del domàs que en puixa tenir hu més per lo tirar del dit domàs.

El manuscrito de Nueva York registra también otro capítulo desconocido del 12 de marzo de 1495 en sus folios 41r-42r que se refiere a lo que han de pagar como tasa quienes han de examinarse como maestros y que tiene que ver con una noticia citada antes, al principio de este apartado, que se registra ese mismo año en las actas municipales. Por lo demás, para el siglo XV este manuscrito no aporta más estatutos. Sin embargo, para los siglos XVI y XVII sí que ofrece información que se desconocía hasta ahora9. De hecho, las siguientes ordenanzas de velluters que se localizan en las actas municipales tras las de 1483 son siete capítulos del 27 de marzo de 1511 dedicados en exclusiva al tema de la tintura y de los pintes (Archivo Municipal de Valencia, Manuals de Consell, A-54). Además, el oficio renunció en 1514 a su capacidad de autonomía del poder municipal para dictar ordenanzas propias (Manuals de Consell, A-56, f. 120v). Y todavía el 30 de enero de 1518, antes de la revuelta ciudadana de las Germanías (1519-1523), se aprobaron cuatro capítulos nuevos para completar normativas anteriores (Manuals de Consell, A-57).

En contrapartida, el manuscrito sí que ofrece otros dos estatutos más anteriores a estas últimas ordenanzas de 1518. Me refiero tanto a una ordenanza del 12 de febrero de 1501 sobre las tasas de examen y la manera en que se debían tejer los damascos (ff. 42r-43r), como a otra del 28 de septiembre de 1510 sobre la elección de mayorales, oidores de cuentas o veedores y la obligatoriedad de que los aprendices acaben el tiempo de contrato que tienen establecidos con los maestros (ff. 44r-50v). Por último, dicho manuscrito reproduce en sus folios $60 \mathrm{v}-63 \mathrm{v}$ unas ordenanzas del 27 de marzo de 1511 que ya habían sido localizadas en las actas municipales.

\section{CONCLUSIONES}

Gracias al libro de ordenanzas de los velluters valencianos conservado en Nueva York se accede a copias coetáneas de los primeros estatutos del oficio del año 1479, con la reprodución parcial del privilegio del rey Fernando el Católico que sólo se conocía por un traslado de 1514. Otra aportación inédita fundamental que ofrece son esos estatutos de 1483 que regularon internamente la cofradía del gremio

\footnotetext{
${ }^{9}$ El listado de estatutos es el siguiente: 1538-02-06 (folios 51r-52v), 1538-02-25 (ff. 52v-53v), 154109-09 (f. 54r), 1542-09-15 (ff. 55v-56v), 1543-02-19/20 (ff. 66r-71v), 1543-02-26 (ff. 64r-65v), 1544-1027 (ff. 57r-58r), 1545-02-28 (ff. 59r-60r), 1561-05-25 (ff. 73v-75v), 1569-05-28 (ff. 75v-77v), 158907-05 (ff. 78r-81v), 1629-03-14 (ff. 84v-90r), 1629-04-29 (ff. 90r-99r), 1629-06-23 (ff. 82r-84v), 1675-01-07 (ff. 101r-108r), 1675-05-27 (ff. 108r-111r), 1675-06-06 (ff. 111r-116v), 1675-06-12 (ff. 116v-118v), 1675-08-20 (ff. 118v-124v), 1676-11-10 (ff. 124v-129v) y 1676-11-20 (ff. 130r-134v).
} 
de velluters bajo la advocación de san Jerónimo. Para el tema de la tecnología sedera destacan los capítulos específicos de las cuartas ordenanzas de 1491 que aluden a los cautivos que trabajan en los tornos de seda o en los telares de damascos, textos desconocidos hasta ahora y que han sido transcritos parcialmente por vez primera aquí dado el interés de su contenido. También los otros muchos capítulos de los siglos XVI y XVII que recoge este manuscrito son muy valiosos para los especialistas en la sedería valenciana.

El contexto histórico que envuelve a este libro de ordenanzas ya ha sido explicado con detalle en las investigaciones publicadas sobre el despegue de la industria sedera valenciana en los siglos XV-XVI que se han citado al principio de este artículo. Los conocimientos existentes sobre la reconstrucción de las fases de la producción sedera y sus características tecnológicas en los paises del Mediterráneo medieval fueron asimismo abordados en profundidad en otro estudio editado hace años ${ }^{10}$. A esta bibliografía esencial que ya estableció en su día comparaciones con los conocimientos existentes en ámbito internacional habría que completarla ahora con dos nuevos trabajos en prensa.

El primero de ellos un estudio monográfico del manuscrito analizado aquí dentro del propio catálogo de la exposición en que ha sido exhibido, y que saldrá editado en breve con doble versión española e inglesa ${ }^{11}$. En este trabajo se transcriben íntegramente todas las ordenanzas salvo los estatutos de la cofradía de 1483 y las de 1491 porque están incompletas. Aquí sin embargo sí que se han transcrito por vez primera algunos de sus capítulos por su interés para el estudio de la tecnología sedera. Se entra asimismo en detallar el auge del comercio sedero en las fuentes fiscales valencianas con diversas alusiones a la Lonja Nueva o Lonja de la Seda de Valencia, edificada durante los años 1483-1536, en pleno despegue de los negocios. De igual forma, se alude en él a la formación del barrio sedero de Valencia en sus orígenes y la evolución del negocio en la ciudad durante el siglo XVI a tenor de las últimas investigaciones llevadas a cabo.

El segundo trabajo en prensa que ayudará a actualizar y completar el análisis del contexto histórico de este manuscrito es una ponencia presentada a un congreso internacional sobre los mercados del lujo y del arte en el Mediterráneo de los siglos XIV-XV'12. En este otro trabajo se interpreta cómo los genoveses intentaron promover la industria de la seda en Barcelona sin éxito allá por los años 1451-1456. El contexto más favorable de Valencia hizo posible el despegue de la sedería local desde 1457 en adelante. También se describe la tipología de tejidos de seda pura para vestir que deja clasificar la fiscalidad valenciana. En ese ámbito y en contraste con las otras capitales de la Corona de Aragón se analiza el papel de Zaragoza como importadora de tejidos valencianos hacia 1500. Por último, se concluye con la función de los tejidos de seda como una industria de lujo al servicio de la demanda mercantil internacional, las new silk draperies a las que se refiere Sergio Tognetti en su obra sobre el mercado sedero en la Florencia del Cuatrocientos ${ }^{13}$. Nada se dice en este segundo trabajo reseñado del manuscrito de Nueva York estudiado aquí, pero se trata sin duda de un análisis de referencia necesario para seguir avanzando en problemas claves de la tecnología sedera del siglo XV que nos descubre el citado manuscrito, a saber, ¿quién diseñaba esos tejidos lujosos? ¿quién dibujaba sus diseños? ¿qué modelos se copiaban? Preguntas éstas y otras sobre las que habrá que seguir profundizando en un futuro inmediato.

\footnotetext{
${ }^{10}$ G. Navarro, El arte de la seda, pp. 5-51.

${ }^{11} \mathrm{G}$. Navarro, Las ordenanzas más antiguas de velluters.

${ }^{12}$ G. Navarro, La producción y el comercio de tejidos.

${ }^{13} \mathrm{~S}$. Tognetti, Un'industria di lusso.
} 


\section{BIBLIOGRAFÍA CITADA}

Navarro Espinach, Germán, El arte de la seda en el Mediterráneo medieval, "En la España Medieval", 27 (2004), pp. 5-51.

Navarro Espinach, Germán, El Col-legi de l'Art Major de la Seda de València, Valencia, Consell Valencià de Cultura-Generalitat Valenciana, 1996.

Navarro Espinach, Germán, El despegue de la industria sedera en la Valencia del siglo $X V$, Valencia, Consell Valencià de Cultura-Generalitat Valenciana, 1992.

Navarro Espinach, Germán, El despegue medieval de la industria de la seda valenciana (1465-1483), Valencia, Universitat de València, 1991.

Navarro Espinach, Germán, La producción y el comercio de tejidos de seda en la Corona de Aragón en el siglo XV, en Actas del congreso internacional "Mercats del luxe, mercats de l'art. La Corona d'Aragó i la Mediterrània en els segles XIV i XV" (Valencia, 7-10 de septiembre de 2010), en prensa.

Navarro Espinach, Germán, Las ordenanzas más antiguas de velluters, 1479-1491. Auge del comercio sedero y edificación de la Lonja Nueva de Valencia, en L'Art dels Velluters. Sederia dels segles XV-XVI, Valencia, Consorci de Museus de la Comunitat Valenciana, en prensa.

Navarro Espinach, Germán, Los orígenes de la sedería valenciana (siglos XV-XVI), Ayuntamiento de Valencia, 1999.

Navarro Espinach, Germán, Los privilegios reales sobre la industria precapitalista en los estados de la Corona de Aragón (siglos XIII-XV), en J. A. Barrio Barrio (ed.), Los cimientos del Estado en la Edad Media, Alicante, Editorial Marfil, 2004, pp. 197-231.

Tognetti, Sergio, Un'industria di lusso al servizio del grande commercio. Il mercato dei drappi serici e della seta nella Firenze del Quattrocento, Florencia, Leo S. Olschki Editore, 2002.

Fecha de recepción del artículo: julio 2011

Fecha de aceptación y versión final: octubre 2011 